\title{
ANALISIS PEMANFAATAN PELAYANAN VCT (VOLUNTARY CONSELING AND TESTING) HIVIAIDS DI RSUD LABUANG BAJI KOTA MAKASSAR
}

\author{
Rika Kurnia Kandacong ${ }^{1}$, Samsualam ${ }^{2}$, Andi Surahman Batara ${ }^{3}$ \\ ${ }^{1}$ Universitas Muslim Indonesia \\ ${ }^{2}$ Universitas Muslim Indonesia \\ ${ }^{3}$ Universitas Muslim Indonesia
}

Alamat Korespondensi: (rikakurnia430@yahoo.com/082343460047)

\begin{abstract}
ABSTRAK
Salah satu upaya dalam strategi nasional penanggulangan HIVIAIDS di Indonesia Tahun 20102014 adalah program pelayanan konseling dan testing HIV sukarela (Voluntary Counselling and Testing-VCT) (KPA, 2010). Jumlah responden dengan HIV dan AIDS (ODHA) semakin meningkat sehinggah kebutuhan terhadap layanan kesehatan juga semakin meningkat. Penelitian ini bertujuan untuk mendapatkan informasi, mengkaji dan menganalisis secara mendalam tentang perilaku pasien HIVIAIDS terhadap pemanfaatan pelayanan Voluntary Counseling and Testing ( VCT) dan analisis strategi pemanfaatan pelayanan VCT (Voluntary Conseling And Testing) di Rumah Sakit Labuang Baji. Jenis Penelitian ini adalah penelitian Kualitatif. Informan dalam penelitian ini adalah 2 responden konselor VCT, Kepala Ruangan VCT, dan 5 Pasien HIVIAIDS. Hasil penelitian menunjukkan pengetahuan pasien HIVIAIDS terhadap pemanfaatan pelayanan VCT sudah baik, Motivasi pasien HIVIAIDS terhadap pemanfaatan pelayanan VCT adalah karena adanya risiko terkena HIVIAIDS. Dukungan keluarga terhadap pemanfaatan pelayanan VCT pada pasien HIVIAIDS sudah baik, Strategi dilakukan petugas kesehatan agar pasien HIVIAIDS mau memanfaatkan pelayanan VCT yang ada di Rumah Sakit adalah melakukan Screening pada semua pasien yang dirawat di Rumah sakit Labuang Baji dengan mengajak pasien yang berisiko untuk ikut konseling secara privasi dan rahasia, Sarana dan Prasarana tehadap pemanfaatan pelayanan VCT di Rumah Sakit Labuang Baji sudah cukup lengkap namun belum maksimal, jumlah konselor yang melayani masih kurang apalagi di lihat dari peningkatan pasien HIVIAIDS yang datang berobat.
\end{abstract}

Kata Kunci : Pemanfaatan Pelayanan VCT, Strategi, HIVIAIDS.

\section{PENDAHULUAN}

Salah satu upaya dalam strategi nasional penanggulangan HIVIAIDS di Indonesia Tahun 2010-2014 adalah program pelayanan konseling dan testing HIV sukarela (Voluntary Counselling and Testing-VCT) (KPA, 2010). Pemanfaatan Klinik VCT di Provinsi Sulawesi Selatan sebanyak 5.704 kunjungan atau 2,8\% dari kunjungan klinik VCT secara Nasional. Jumlah penderita baru HIVIAIDS hingga Juni 2018 di Kota Makassar mencapai 354 responden. Data tersebut dari jumlah 21.725 responden yang datang kelayanan konseling dan testing HIV di Kota Makassar dari JanuariJuni 2018, jumlah tersebut diprediksi masih akan terus bertambah sepanjang tahun ini. Apa lagi menurut catatan Dinas Kesehatan dalam kurun waktu tiga tahun terakhir di Kota Makassar, jumlah penderita HIV terus meningkat. Tahun 2015 tercatat 665 HIV Positif baru, tahun 2016 naik menjadi 773, lalu tahun 2017 naik lagi sebanyak 1038 HIV Positif.(Dinas Kesehatan Kota Makassar, 2018). Menurut Data dari Rumah Sakit Labuang Baji yang diambil dari JanuariOktober 2018 pasien ODHA yang rutin melakukan pemeriksaan VCT sebanyak 2.587, dan dilihat dari data kunjungan Rumah Sakit untuk Pasien HIV setiap bulannya selalu meningkat. Sehinggah Penelitian ini bertujuan untuk mengetahui Pemanfaatan Pelayanan Voluntary Counseling and Testing( VCT) di Rumah Sakit Labuang Baji Kota Makassar

\section{BAHAN DAN METODE}

Lokasi, Populasi, dan Sampel

Penelitian yang digunakan adalah penelitian kualitatif dengan pendekatan analisis isi (content analysis). Penelitian ini dilaksanakan di Rumah Sakit Umum Daerah Labuang Baji Kota Makassar, pada tanggal 2 Februari s/d 2 Maret 2019. Populasi dalam penelitian ini adalah Petugas VCT yang bekerja di Rumah Sakit Labuang Baji Kota Makassar dan Pasien HIVIAIDS yang berkunjung atau berobat di Rumah Sakit Labuang Baji Kota Makassar. Kriteria inklusif
a. Bersedia menjadi responden
b. Pasien positif HIVIAIDS.
c. Berada di rumah sakit pada saat penelitian 
Tabel 1. Karakteristik Informan di Rumah Sakit Umum Daerah Labuang Baji Kota Makassar $(n=8)$.

\begin{tabular}{|c|c|c|c|c|c|c|}
\hline No & Inisial & $\begin{array}{c}\text { Jenis } \\
\text { kelamin }\end{array}$ & $\begin{array}{c}\text { Usia } \\
\text { (Tahun) }\end{array}$ & Pendidikan & Alamat & Ket. \\
\hline 1 & SM & L & 47 & SKM & Makassar & IK \\
2 & HM & P & 39 & Ners & Makassar & IP \\
3 & HR & P & 50 & Perawat & Makassar & IP \\
4 & NL & P & 35 & SMA & Makassar & IB \\
5 & ML & L & 26 & SMA & Makassar & IB \\
6 & MS & L & 28 & S1 & Maros & IB \\
7 & MF & L & 49 & S1 & Barru & IB \\
8 & SB & L & 52 & S1 & Makassar & IB \\
\hline
\end{tabular}

Data diperoleh secara primer melalui observasi langsung dan wawancara mendalam dengan 8 responden informan yang terbagi dalam 3 kelompok informan, yaitu informan biasa 5 responden, informan pendukung 2 responden, dan informan kunci 1 responden. Peneliti mengambil 5 responden informan biasa yaitu Pasien HIVIAIDS yang datang berobat di RSUD Labuang Baji. Sedangkan untuk informan pendukung ada 2 responden yaitu Konselor VCT dan Kepala Ruangan VCT. Dan untuk Informan Kunci ada 1 responden yaitu Penanggung Jawab Konselor VCT RSUD Labuang Baji.

\section{Pengetahuan}

Berdasarkan hasil penelitian tentang pengetahuan pasien HIVIAIDS tentang pemanfaatan pelayanan VCT dapat disimpulkan bahwa sudah baik sehingga mereka sudah mau memanfaatkan pelayanan VCT yang ada, hal ini sesuai dengan pernyataan inforrman:

"Yang saya ketahui tentang VCT itu adalah di mana suatu bentuk pelayanan yang ada di rumah sakit khususnya untuk mengetahui status HIV seseresponden"(NL, 35 Tahun, 22 Februari 2019).

Sedangkan Pengetahuan pasien sendiri tentang HIVIAIDS sudah baik, secara garis besar mereka tahu apa itu HIVIAIDS hal ini sesuai dengan pernyataan informan :

"HIVIAIDS itu human immudifiency virus yang di mana yang menyerang system kekebalan tubuh sedangkang AIDS sekumpulan gejala penyakit dari HIV" (NL, 35 Tahun, 22 Februari 2019).

Kemudian Pengetahuan Pasien HIVIAIDS tentang alur pemeriksaan VCT pada awal pemeriksaan masih kurang mereka hanya datang dan meminta arahan kepada petugas, hal ini sesuai dengan pernyataan informan :

"tidak, saya cuman di arahkan saja sama petugasnya, owh saya jarang pergi melakukan pemeriksaan jadi saya selalu bertanya sama petugasnya" (MS, 28 Tahun, 21 Februari 2019).

Dari jawaban beberapa informan menunjukkan bahwa pengetahuan pasien HIVIAIDS terhadap pemanfaatan pelayanan VCT itu sudah baik, namun ada masih ada beberapa informan yang tidak tahu apa itu VCT yang mereka tahu adalah pemeriksaan HIV yang di lakukan di Rumah Sakit.

\section{Motivasi}

Berikut adalah pernyataan informan tentang apa yang membuat mereka ingin melakukan pemeriksaan VCT:

"waktu itu kan saya pekerjaannya sebagai waria baru saya pergi coba coba ternyata saya kena HIV kemudian saya rutin berobat dan tidak melakukan pekerjaan itu lagi".......(ML,26Tahun,22 Februari 2019)

Dari pernyataan informan diatas dapat disimpulkan bahwa motivasi mereka untuk melakukan pemeriksaan VCT karena adanya risiko terkena HIVIAIDS, namun ada juga informan mau melakukan pemeriksaan HIVIAIDS setelah mereka datang berobat kerumah sakit kemudian di rujuk ke rumah sakit yang melakukan pelayanan VCT berikut adalah pernyataan informan:

"karena saya sakit awalnya tidak tahu dan jarang pergi periksa baru langsung masuk di rawat inap, jadi setahu saya cuman disini saja bisa lakukan pengobatan jadi saya langsung kesini" (MS, 28 Tahun, 21 Februari 2019).

Dari beberapa jawaban informan menunjukkan bahwa Motivasi pasien HIVIAIDS terhadap pemanfaatan pelayanan VCT karena adanya risiko terkena HIVIAIDS dan mereka mendapatkan informasi tentang pemeriksaan VCT dari petugas kesehatan, internet, rujukan dari rumah sakit lain dan teman sesama pengidap HIVIAIDS.

\section{Dukungan Keluarga}

Berikut pernyataan informan tentang pertanyaan peneliti apakah keluarga anda 
mendukung untuk melakukan pemeriksaan VCT :

"iyaa keluarga saya sangat mendukung bahkan sekali kali, saya datang periksa sama istri saya" (SB, 52 Tahun, 23 Februari 2019).

Dari pernyataan dari beberapa informan diatas dapat disimpulkan bahwa adanya dukungan dari keluarga yaitu dukungan memberi nasehat, emosional dan pemberian bantuan dengan menemani untuk melakukan pemeriksaan VCT, namun ada juga informan yang merasa tidak mendapat dukungan penuh dari pihak keluarganya, berikut pernyataan informan :

"tidak ada dukungan keluarga saya sendiri yang pergi tidak ada yang mengantar kecuali beberapa keluarga eeee dari almarhum suami yang tahu tapi tetap ka sendiri" "(NL, 35 Tahun, 22 Februari 2019).

Sehingga dari pernyataan beberapa informan diatas dapat di simpulkan bahwa keluarga sangat mendukung untuk melakukan pemeriksaan VCT adapun bentuk dukungan keluarga adalah seperti dukungan emosional dengan memberikan perhatian dan semangat serta pemberian bantuan seperti mendampingi saat pemeriksaan VCT.

\section{Strategi Petugas Kesehatan}

Kemudian peneliti menanyakan Bagaimana Strategi yang dilakukan petugas kesehatan agar pasien HIVIAIDS mau memanfaatkan pelayanan VCT yang ada dirumah sakit, berikut adalah pernyataan informan pendukung:

"eee...apa, klo strateginya anu eee seperti LSM toh ada namanya pelayanan jangkauan ada kunjungan seperti mobile dia anumi dia arahkan kemudian dilakukan pemeriksaan di sini, kalau di rumah sakit adalah menerima rujukan dan melakukan screening pada semua pasien yang dirawat siapapun di kelas manapun " (HR, 50 Tahun, 23 Februari 2019).

Strategi yang dilakukan petugas kesehatan agar pasien HIVIAIDS mau memanfaatkan pelayanan VCT yang ada di Rumah Sakit adalah melakukan Screening pada semua pasien yang dirawat di Rumah sakit Labuang Baji dengan mengajak pasien yang berisiko untuk ikut konseling secara privasi dan rahasia, selain itu dan Rumah Sakit Labuang Baji merupakan salah satu rumah sakit rujukan pertama dari Puskesmas maupun Rumah Sakit Daerah yang ada di Sulawesi Selatan yang menerima rujukan pasien HIVIAIDS.

\section{Ketersedian Sarana dan Prasarana}

Berdasarkan hasil wawancara mendalam, peneliti menanyakan Bagaimana dengan ketersedian Sarana dan Prasarana penunjang pelayanan VCT di Rumah Sakit ini, berikut adalah pernyataan informan kunci :

........kemudian untuk ketersedian sarana ditingkatan kalau puskesmas itu eee ada kewenangan terbatas bisa memeriksa ketika ada namanya kan ada namanya program kita pisahkan antara HIV dengan AIDS, HIV itu bisa tidak ditangani di rumah sakit artinya jadi dia bisa dirawat jalan jadi bisa ditangani di puskesmas ketika dia masuk dalam tahap AIDS, kalau untuk rumah sakit labuang baji karena kami adalah rumah sakit rujukan Sulawesi selatan......" "(SM, 47 Tahun, 21 Februari 2019).

Dari pernyatan informan kunci diatas dapat di simpulkan bahwa Sarana dan Prasarana untuk penunjang pelayanan VCT di Rumah Sakit Labuang Baji sudah lengkap namun dari segi sumber daya manusia misalnya saja dokter spesialis yang masih kurang lengkap sehinggah jika ada pasien HIVIAIDS yang harus di tangani lebih lanjut maka mereka merujuk ke Rumah Sakit tipe A yaitu Rumah Sakit Wahidin, namun hal ini tidak sejalan dengan pernyataan informan pendukung : "kalau sarana dan prasarana itu belum maksimal seperti ada pemeriksaan laboratorium ada yang tidak lengkap, biasanya kalau ada pasien yang mau pemeriksaan lab yang cukup lengkap kita rujuk keluar" (HM, 39 Tahun, 21 Februari 2019)

Sehinggah dapat disimpulkan bahwa bahwa Sarana dan Prasarana untuk penunjang pelayanan VCT di Rumah Sakit Labuang Baji sudah cukup lengkap namun belum maksimal ada beberapa hal yang memungkinkan pasien harus di rujuk ke Rumah Sakit Wahidin seperti Pemeriksaan Laboratorium dan Sumber Daya Manusia seperti Dokter Spesialis.

\section{Keterampilan Petugas VCT/Konselor}

Berikut adalah pernyataan informan tentang keterampilan dan pengalaman konselor di Rumah Sakit Labuang Baji: 
"kalau saya sudah kurang lebih 5 tahun jadi konselor disini, jadi sudah cukup tahu semuanya" (HM, 39 Tahun, 21 Februari 2019).

melakukan pelayanan VCT di Rumah Sakit ini berikut adalah pernyataan informan pendukung:

"hanya 2 responden saja satu rawat inap satu rawat jalan" (HM, 39 Tahun, 21 Februari 2019)

untuk memberikan inisiasi kepada pasien untuk melakukan pemeriksaan HIVIAIDS.

Dari perkembangan penelitian, peneliti menanyakan apakah konselor yang ada sudah cukup untuk melayani pasien HIVIAIDS, berikut adalah pernyataan informan pendukung :

"klo konselor itu masih kurang, kan kemarin itu saya ikut konselor karena di tunjuk langsung untuk pelatihan kan kalau saya dulu kerja sebagai perawat..." (HM, 39 Tahun, 21 Februari 2019).

\section{PEMBAHASAN}

Pengetahuan menjadi salah satu factor predisposisi yang mempengaruhi pemanfaatan pelayanan VCT oleh masyarakat. Pengetahuan tesebut berupa informasi yang diketahui oleh informan tentang cara penularan HIVIAIDS serta tujuan, manfaat dan alur pelayanan VCT. Berdasarkan hasil penelitian yang di peroleh bahwa pengetahuan pasien HIVIAIDS tentang pelayanan VCT sudah baik, hal ini disebabkan karena mereka merasa berisiko tertular HIVIAIDS sehinggah mereka mau memanfatkan pelayanan VCT yang ada, walaupun ada beberapa pasien HIVIAIDS yang datang untuk memanfaatkan pelayanan VCT karena rekomendasi dari puskesmas, rujukan dari rumah sakit lain,maupun LSM (Lembaga Swadaya Masyarakat yang secara aktif memberikan saran kepada mereka agar mengikuti pemeriksaan VCT tanpa tahu tentang tahapan pelayanan VCT tesebut.

Motivasi merupakan satu penggerak dari dalam hati seseresponden untuk melakukan atau mencapai sesuatu tujuan. Motivasi juga bisa di katakan sebagai rencana atau keinginan untuk menuju kesuksesan menghindari kegagalan hidup. Motivasi dapat berupa motivasi intristik dan ekstrinsik. Di samping itu motivasi juga akan sangat di pengaruhi dari luar (eksternal). Berdasarkan hasil penelitian yang diperoleh bahwa motivasi pasien HIVIAIDS untuk memanfaatkan pelayanan VCT adalah karena adanya risiko terkena HIVIAIDS dan mereka mendapatkan informasi tentang pemeriksaan VCT dari petugas kesehatan, internet, rujukan dari rumah sakit lain dan teman sesama pengidap HIVIAIDS.

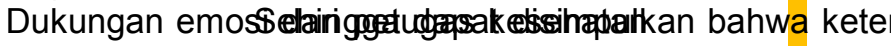
merupakan ketersedian sumber daya yang memberikan kenyamanan fisik maupun psikologis. Menurut Notoatmodjo (2012), emosi yang sehat tercermin dari kemampuan seseresponden mengekpresikan dan hal tersebut dapat menjadi motivasi dan rasa nyaman seseressomolegga dapikt disinimgilkan bahwa jumla memanfaatkan sarana pelayanan kesehatan, seperti klinik VCT.

Dari hasil penelitian menunjukkan bahwa Sarana dan Prasarana untuk penunjang pelayanan VCT di Rumah Sakit Labuang Baji sudah cukup lengkap namun belum maksimal ada beberapa hal yang memungkinkan pasien harus di rujuk ke Rumah Sakit Wahidin seperti Pemeriksaan Laboratorium dan factor lain yaitu Sumber Daya Manusia seperti Dokter Spesialis.

Menurut green (2005), ketersediaan sarana dan prasarana merupakan factor pendukung yang memungkingkan suatu tujuan dapat terlaksana. Factor pendukung tersebut mencakup sumber daya yang perlu untuk melakukan perilaku kesehatan. Sumber daya itu antara lain meliputi ketersedian sarana dan prasarana, ketercapaian berbagai sumber daya, ketersedian obat, kebijakan pemerintah. Menurut pedoman layanan VCT dari kemenkes, konselor VCT berasal dari tenaga kesehatan atau non kesehatan yang telah mengikuti pelatihan terkait VCT. Selain itu di butuhkan jumlah konselor yang cukup agar layanan dapat segera dilakukan sehinggah klien tidak harus menunggu lama.

Dari hasil wawancara mendalam di dapatkan bahwa keterampilan dan pengalaman konselor dalam melayani pasien HIVIAIDS sudah baik karena sebelum mereka menjadi konselor terlebih dahulu di lakukan pelatihan oleh Kemenkes dan mereka melakukan tugas sesuai dengan standar SOP yang ada, namun dari segi jumlah konselor yang melayani masih kurang apalagi di lihat dari peningkatan pasien HIVIAIDS yang datang berobat.

Hasil pertemuan Harare-Zimbabwe tahun 2001 menyebutkan bahwa terdapat 4 jenis konselor yang kompeten dalam memberikan layanan konseling berdasarkan model implementasi dan strategi untuk meningkatkan layanan VCT yaitu konselor sebaya (peer counselor), konselor awam (lay counselor), konselor professional (professional counselor), dan konselor senior (senior counselor). Hasil studi di Afrika selatan menemukan masalah 
pada layanan VCT yang mirip dengan hasil penelitian ini, yaitu masalah yang meliputi tidak jumlah konselor yang kurang.

\section{KESIMPULAN}

1. Pengetahuan pasien HIVIAIDS terhadap pemanfaatan pelayanan VCT itu sudah baik.

2. Motivasi pasien HIVIAIDS terhadap pemanfaatan pelayanan VCT karena adanya risiko terkena HIVIAIDS

3. Dukungan keluarga terhadap pemanfaatan pelayanan VCT pada pasien HIVIAIDS sudah baik.

4. Strategi yang dilakukan petugas kesehatan untuk meningkatkan pemanfaatan pelayanan VCT adalah melakukan Screening pada semua pasien yang dirawat di Rumah sakit Labuang Baji dengan mengajak pasien yang berisiko untuk ikut konseling secara privasi dan rahasia.

\section{DAFTAR PUSTAKA}

Affandhy, Syakhrul. 2015. Analisis Pemanfaatan Voluntary Counseling And Testing (Vct) Pada Kelompok Risiko Tertular HIVIAIDS Di Kota Pare-Pare. Tesis, Program Pascasarjana Universitas Hasanuddin Makassar, (online) (hhtp repository. Unhas. Ac id4001digilib filesdisk1411_syahrulaf-20526-1-15-syhakh_)pdf. Diakses 28 Agustus 2018

Buku Panduan Hari AIDS Sedunia Tahun 2015., (online), (httpwww. Dephub.go.id public file supload spotstsposttspostbodybuku-panduan-has-2015.pdf, di akses 28 Agustus 2018

Dinkes Kota Makassar. 2013. Profil Kesehatan Kota Makassar Tahun 2012,. (online), (http: // dinkes kota Makassar.net / download/718 Gabung \%20 profil \%202013.pdf. diakses 28 Agustus 2018

Dirjen PP \& PL Kemenkes RI. A 2010. Pedoman Penerapan Konselin Dan Tes HIV (Online), (https. Linkaisd.files. wordpress.com201409buku-modul-peserta.pdf. di akses 28 Agustus 2018

Green, Lawrence. 1980. Health Education Planning, A Diagnostic Approuch. The John Hopkins: Mayfield Publishing Co

Komisi Penanggulangan AIDS, 2007. Strategi Nasional Penanggulangan HIV Dan AIDS 2007-2010. The National HIV \& AIDS Strategy 2007-2010 (The National HIVIAIDS Strategy 2007-2010 (Indonesia). Pdf

Laporan Perkembangan HIV-AIDS Triwulan II Tahun 2013, (online), (http://www. Depkes. go.id/ resources/download/pusdatin/infodatin/infodatin20AIDS.pdf. diaskes 28 Agustus 2018

Metodologi Penelitian Kesehatan. PT. Rineka Cipta: Jakarta

Notoatmodjo, Soekidjo. A. 2013. Pendidikan dan Perilaku Kesehatan. PT. Rineka Cipta Jakarta

Pangaribuan, Sariana. 2011. Analisis Determinan Proxi Dalam Pemanfaatan Klinik Voluntary And Counseling (VCT) Di Distrik Sorong Utara Kota Sorong. Program Pascasarjana UNHAS: Makassar

Pedoman Nasional Tes dan Konseling HIV dan AIDS, (Online), httppppl. Depkes.Go.id Asset Download pedoman \%20okt\% 20\%hiv20kawanua \%20 des \%202013 \%20\% 20\%rev\%20290114\%201-5.Pdf. di akses 1 September 2018

Permenkes, 2014. Peraturan Mentri Kesehatan Republik Indonesia Nomor 74 Tahun 2014 Tentang Pedoman Pelaksanaan Konseling dan Tes HIV, (Online), http saids free, usaid, govsites default fileshts policy Indonesia 2014.pdf. di akses 1 September 2018

Sugiyono, 2014. Metode Penelitian Kuantitatif dan Kualitatif. Penerbit Alfabeta: Bandung. 